\title{
APRENDIZAGEM DAS REGULARIDADES ORTOGRÁFICAS: ESTRATÉGIAS PARA RESOLVER DESAFIOS DESENVOLVIDAS POR ALUNOS DURANTE A REALIZAÇÃO DE JOGOS ORTOGRÁFICOS
}

\author{
Shirley Thayza Soares de Souza \\ Rosy Karine Pinheiro de Araújo \\ Ana Cláudia Rodrigues Gonçalves Pessoa \\ Universidade Federal de Pernambuco
}

DOI: https://doi.org/10.31692/2358-9728.VICOINTERPDVL.2019.0113

\section{Resumo}

O objetivo geral deste estudo foi analisar as estratégias que os alunos desenvolveram para resolver os desafios durante a realização de jogos ortográficos e como essas estratégias interferiram na aprendizagem das regras trabalhadas. Aplicamos 06 jogos de ortografia, abordando regularidades contextuais M/N, C/QU e R/RR. Participaram das sessões de jogos 20 sujeitos (10 crianças do $3^{\circ}$ ano e 10 crianças do $5^{\circ}$ ano) do Ensino Fundamental I da rede municipal de ensino da cidade do Recife. Mediante a análise categorial temática de Bardin como técnica de análise do conteúdo, nossos resultados apontaram que durante as aplicações dos jogos, a análise fonológica, a correção das palavras e a verbalização das regras foram estratégias utilizadas entre os sujeitos participantes. Ao final do estudo, evidenciamos um avanço considerável da maioria dos alunos quanto a aprendizagem das regras, demonstrando o progresso positivo e significativo no que tange a aprendizagem dessas regularidades da língua portuguesa.

Palavras - chave: regras ortográficas, jogos, mediação. 


\section{INTRODUÇÃO}

O ensino da ortografia levanta uma série de questões que endossam o coro das práticas pedagógicas significativas que possibilitem, de fato, a aprendizagem dos sujeitos. $\mathrm{O}$ ensino da norma ortográfica de nossa língua materna perpassa por muitas discussões, no entanto, compreender o funcionamento dela é um direito dos sujeitos, assim como a assimilação do sistema de escrita alfabética (SEA).

Sabendo que a norma ortográfica é uma convenção social, o trabalho dela exige uma abordagem que facilite a internalização de todas as suas especificidades. De acordo com Morais (2005), um acordo social determinou que nosso sistema de escrita incorporasse formas únicas na grafia das palavras, porém, isso não se dá de forma homogênea. "Por ser uma convenção que contém não só regras como irregularidades, muitas pessoas imaginam que a ortografia é um acidente histórico desnecessário, que apenas serve para dificultar a tarefa de quem escreve" (MORAIS, 2005, p. 15).

No que tange as notações regulares da língua, o estudo efetivo possibilita uma maior segurança aos sujeitos, uma vez que elas obedecem a um padrão onde é possível prever como se dará a escrita de determinada palavra mesmo sem conhecê-la. Para isso, a observação e a reflexão se fazem necessárias para a compreensão do uso das regularidades ortográficas de nossa escrita, ampliando o entendimento das correspondências letra-som. Em síntese, "a ortografia da língua portuguesa é um sistema convencional de representação que prescreve a forma correta de se escrever as palavras, incluindo as letras, a acentuação gráfica e a segmentação das palavras" (TONELI, 2014. p. 77).

Em sua tese de doutoramento, Morais (1995) dialoga sobre três tipos de correspondências regulares em nossa língua: diretas, contextuais e morfológicos-gramaticais. Essas regularidades seguem uma lógica comum nos seus princípios explicativos referentes à norma, ao contrário das irregularidades da língua que demandam a memorização das palavras pela ausência de um padrão. “Com base na distinção do que é regular e irregular, o professor poderá organizar mais claramente seu trabalho, decidindo o que o aluno precisa memorizar e o que ele precisa compreender" (MORAIS, 2003, p. 28).

O ensino da ortografia nas escolas brasileiras ainda é um desafio para crianças e adultos em fase de escolarização. Durante a educação básica, muitas dúvidas referentes à língua acabam se internalizando negativamente nos sujeitos, criando uma espécie de bloqueio 
ou aversão a língua escrita; essas dúvidas acabam se tornando remanescentes ao longo da vida dos indivíduos - o que deixa a relação com a língua menos atrativa.

Segundo Morais e Silva (2005, p. 61), “em nossa sociedade, e em particular no contexto escolar, a correção ortográfica continua sendo cobrada dos usuários da língua escrita”, nessa perspectiva, àqueles que não atendem à norma são alvos de críticas, uma vez que "escrevem com muitos erros". Por sua vez, a escola deve assumir o importante papel de ensinar os alunos a "escrever certo".

Nesse sentido, o ensino da ortografia nas escolas deve ser regido através da reflexão, engajando os estudantes a se apropriarem, de fato, do objeto de conhecimento de modo sistemático, em detrimento das metodologias tradicionais e mecanicistas baseadas exclusivamente na repetição e memorização dos conteúdos.

Como auxílio à aprendizagem da norma, os jogos são instrumentos importantes à prática pedagógica. Com relação a ortografia, os jogos viabilizam a sistematização das regras de modo lúdico, ajudando os alunos a fazerem as correspondências entre fonemas e grafemas através do material concreto, onde é possível visualizar e refletir sobre essas relações divergentes das correspondências orais.

Desta maneira, o uso de jogos no processo de ensino fomenta a aprendizagem dos sujeitos, se pondo como uma forma de incremento às aulas, cabendo aos docentes a mobilização da turma para a construção do conhecimento.

Os jogos de regras ainda são recursos didáticos que motivam os alunos a se envolverem mais durante as aulas, além disso, por seu caráter competitivo, tendem a deixar as aulas mais atrativas. Compreendendo que os desafios já estão presentes no próprio recurso, nos perguntamos se as crianças participantes dos jogos procuram criar estratégias para resolver as questões postas pelo jogo, no nosso caso as questões ortográficas; caso criem essas estratégias, como fazem e quais são elas?

Assim o objetivo do estudo foi analisar as estratégias que os alunos desenvolvem para resolver os desafios durante a realização de jogos e como essas estratégias interferem na aprendizagem da regra ortográfica. 


\section{O Ensino da Ortografia}

Segundo Morais (2005), o ensino da ortografia continua sendo um desafio aos professores, mesmo em face a difusão da importância de práticas pedagógicas que possibilitem a assimilação dos conteúdos de maneira dinâmica e interativa por meio de uma didática pensada às necessidades dos educandos.

Durante a realização e a conclusão de sua pesquisa em meados de $1998^{1}$, Morais (2005) observou que o ensino da ortografia pouco mudou nesse ínterim, muitas práticas do passado se fazem presentes nos modelos de ensino atuais, onde a ortografia é caracterizada como uma área de conhecimento excludente, separando os "bons" dos "ruins" por assim dizer.

Entrementes, entendia-se que apenas uma única perspectiva serviria como suporte à aprendizagem das regras ortográficas - a memorização -, cujas especificidades eram trabalhadas de modo deficitário à compreensão efetiva. No entanto, segundo Morais, apenas os casos irregulares dependem exclusivamente de memorização:

No caso das irregularidades, não há regra ou princípio gerativo que se aplique de maneira mais ou menos generalizada ao conjunto de palavras de nossa língua. Quando grafemas autorizados pela norma se devem unicamente a questões históricas - à etimologia da palavra ou à tradição de uso -, temos que memorizar as formas corretas. Ou consultar o dicionário, no caso de dúvidas muito compreensíveis quando temos que escrever palavras menos frequentes na escrita diária (MORAIS, 2005, p. 19).

No caso das correspondências fonográficas regulares (casos que têm regras), elas não dependem da memorização e, sim, de uma abordagem de ensino que favoreça o domínio da norma ortográfica. O ensino das notações regulares deve ser pensado para que os alunos criem uma consciência sobre como se dá o processo de análise da língua, entendendo que as dificuldades ortográficas podem ser superadas a partir da aprendizagem das regras.

Entendemos que a compreensão do funcionamento do sistema notacional de escrita conecta os aprendizes ao mundo externo, tornando-os agentes dominantes da língua e produtores de conhecimento, porém, certas posturas e/ou práticas pedagógicas continuam calcadas em metodologias de ensino deficitárias, com a ausência de momentos de reflexão

1 Pesquisa realizada por Morais e Biruel com o intuito de investigar professoras de $2^{\circ}, 3^{\circ}$ e $4^{\circ}$ ano da rede municipal de ensino da cidade do Recife no qual estavam desenvolvendo o ensino de ortografia. 
que propiciem a construção da criticidade dos sujeitos. Pois, com alcance da hipótese alfabética da escrita, os educandos já começam a confrontar-se a uma outra seara de particularidades da língua - a ortografia. Ademais, os conhecimentos normativos necessitam de um tratamento alicerçado na reflexão para o desenvolvimento da capacidade cognitiva em relação ao objeto de conhecimento cujo processo esteja em fase de assimilação/construção.

Para Morais (2003), os professores devem estimular seus alunos no desenvolvimento da explicitação da norma através da promoção de diferentes situações pedagógicas que beneficiem a aprendizagem dos sujeitos. Levando em consideração essa questão, compreendemos que os docentes devem lançar mão da observação dentro da sala de aula, ficando atento às dificuldades ortográficas que surgem no dia a dia; tomando essas dificuldades como indicadores de que é necessário fazer uma intervenção para superar esses obstáculos.

Segundo Almeida (2013, p. 23), "até pouco tempo atrás, as práticas de ensino, inclusive o ensino da língua, concebiam, sem qualquer questionamento, o aprendiz como um ser passivo frente ao ato do conhecimento". Tomando como base esse pressuposto, é certo afirmar que o ensino da ortografia nas escolas teve pouca evolução no que se refere a uma metodologia de ensino capaz de instigar a reflexão sobre à norma de modo eficiente, com o objetivo de dar outra visão à ortografia, fugindo das velhas práticas orientadas pela exigência demasiada de cópias textuais com a única intenção de avaliar a grafia, sem ao menos verificar se o nível de explicitação quanto a aprendizagem da língua se desenvolveu nos indivíduos. Sobre a aprendizagem da ortografia, Almeida (2013) dialoga que:

\footnotetext{
As pesquisas apontam para o fato da aprendizagem da ortografia não estar calcada apenas na memorização [...] há aspectos da norma que são regidos por regularidades, tendo princípios gerativos que, se compreendidos, facilitam a escrita das palavras. Há também, dentro da norma, palavras que não seguem nenhuma lógica, são escritas de acordo com as convenções, ou seja, são arbitrárias e precisam ser memorizadas ou então os escritores devem recorrer a fontes em que haja a escrita conforme a norma culta (ALMEIDA, 2013, p.35) .
}

Sendo assim, através de aulas mais reflexivas, o ensino da ortografia pode ser conduzido através do entendimento de que há casos regulares e irregulares presentes na norma, deixando explícito que a aprendizagem delas nos ajudarão a entender as 
correspondências de nossa língua, o que facilitará nossa comunicação escrita e, consequentemente, nossa relação com a sociedade de modo geral.

\section{O uso de jogos didáticos como recurso facilitador do processo de aprendizagem da ortografia}

Com um vasto leque de possibilidades para facilitação do processo de aprendizagem, a Educação configura a busca por métodos de ensino capazes de instigar o interesse dos aprendizes na aquisição do novo conhecimento - especialmente os que seguem normas/padrões, como é o caso da ortografia. Desta forma, para ajudar os alunos a refletirem sobre tais regras, o docente deve buscar recursos que estimulem a curiosidade e o interesse dentro da sala de aula - a destacar o uso de jogos didáticos. Almeida (2013) observou que o uso de jogos didáticos dentro da sala de aula é bastante limitado, mostrando que a queixa dos docentes vem da dificuldade de mediar os momentos de aplicação dos jogos, destacando a inquietude que esse recurso traz à sala de aula. Todavia, os jogos são peças-chave à prática pedagógica e fortes aliados à aprendizagem dos sujeitos. Para Vygotsky:

A criança que sempre participou de jogos e brincadeiras grupais saberá trabalhar em grupo; por ter aprendido a aceitar as regras do jogo, saberá também respeitar as normas grupais e sociais. É brincando bastante que a criança vai aprendendo a ser um adulto consciente, capaz de participar e engajar-se na vida de sua comunidade (VYGOTSKY, 1994, p.82).

Levando em consideração os postulados de Vygotsky, compreendemos que o processo de aprendizagem se dá de forma mediada, onde os processos interativos entre professor e aluno favorecem a aprendizagem. Nessa dialética, os professores trabalham no desenvolvimento potencial da criança com relação ao seu nível de desenvolvimento real. $\mathrm{Na}$ sua teoria da Zona de Desenvolvimento Proximal (ZDP), Vygotsky (1994, p. 97) diz que: "A Zona de Desenvolvimento Proximal define aquelas funções que ainda não amadureceram, mas que estão em processo de maturação, funções que amadurecerão, mas que estão, presentemente, em estado embrionário".

Essa epistemologia nos revela a necessidade do aprimoramento das práticas pedagógicas, defendendo uma didática mediada que acione todas as capacidades cognitivas 
dos sujeitos durante o processo de aprendizagem. Portanto, o uso de jogos como instrumento de facilitação da prática pedagógica transforma o processo de ensino, deixando-o prazeroso e atrativo, uma vez que a sala de aula é transformada em um ambiente de ludicidade e de interação entre os alunos e o professor mediador.

Desta maneira, conforme supracitado, esta ferramenta auxilia o processo de aprendizagem para o alcance dos objetivos didáticos. Nesse sentido, as situações-problema trazidas pelos jogos estimulam a elaboração de estratégias de resolução dos desafios propostos, o que ajuda os aprendizes a formularem hipóteses para alcançar um resultado favorável durante sua aplicação; possibilitando a consolidação dos saberes adquiridos durante o processo.

Podemos dizer, então, que o jogo provoca uma relação de equilíbrio nos sujeitos, acionando os processos de acomodação e assimilação teorizados por Piaget (2013); nessa lógica, o jogo estimula o pensamento dos aprendizes, fazendo-os criar uma linha de raciocínio durante o jogo, construindo assim o seu conhecimento. A partir dessa visão, podemos destacar que os jogos também favorecem o espírito coletivo, não só por estimular a ética e a subordinação à regras - atitudes que fazem parte da vida em sociedade -, mas, também, por criar uma atmosfera que induz os sujeitos a pensarem em estratégias eficazes através dos diálogos e das tomadas de decisões em conjunto, uma vez que cada membro do grupo se ajuda para chegar ao objetivo em comum, viabilizando, assim, a construção do conhecimento coletivo - o que demanda o comprometimento individual dos sujeitos participantes.

\section{METODOLOGIA}

Para a realização desta pesquisa utilizamos a análise de conteúdos proposta por Bardin, que possibilitou a análise categorial dos resultados obtidos. Segundo Bardin (1977, p. 37), a análise de conteúdo se configura como "um conjunto de técnicas de análise das comunicações que visa obter, por procedimentos sistemáticos e objetivos de descrição do conteúdo das mensagens, indicadores que permitam a inferência de conhecimentos relativos às condições de produção destas mensagens", ou seja, mecanismos que buscam a validação do objetivo esperado inicialmente frente aos dados obtidos durante o desenvolvimento da pesquisa. 
O trabalho foi desenvolvido em duas turmas de escolas municipais do Recife, sendo uma turma do $3^{\circ}$ ano e outra do $5^{\circ}$ ano. Os alunos foram submetidos a um ditado lacunado inicial, no qual buscou-se identificar quais dificuldades ortográficas eram mais recorrentes nas duas turmas. Após o levantamento dessas dificuldades e, posteriormente, da seleção dos 24 sujeitos participantes (aqueles que apresentavam maior dificuldade nas regras selecionadas para a pesquisa), verificou-se que a maior parte tinha dúvidas quanto a utilização das regularidades ortográficas contextuais do $\mathrm{M} / \mathrm{N}, \mathrm{C} / \mathrm{QU}$ e R/RR. A partir desse levantamento, partimos para a seleção e aplicação dos jogos didáticos que trabalhariam essas regras com os sujeitos participantes da pesquisa. Os jogos escolhidos foram adaptados de Almeida (2013).

Foram realizados 09 encontros em cada turma para a aplicação dos jogos, todos previamente agendados com as professoras regentes das salas de aula. As observações pautaram-se na identificação das estratégias desenvolvidas pelos alunos para resolver os desafios durante a realização dos jogos ortográficos e como essas estratégias interferiram na aprendizagem das regras ortográficas trabalhadas. Posto isto, conforme o objetivo proposto pelos jogos de ortografia, o processo se deu de forma mediada por uma professora pesquisadora em formação, onde buscou-se fazer uma reflexão sobre a importância da aprendizagem da regra ortográfica.

Os jogos desenvolvidos nessa investigação foram divididos em duas categorias: jogos de classificação e jogos de escrita. Ou seja, cada uma das três regularidades contextuais escolhidas de acordo com a análise dos ditados, foram contempladas com dois jogos distintos. Primeiramente foram aplicados os jogos de classificação e, posteriormente, os de escrita, obedecendo a ordem: M/N; C/QU; R/RR.

Após a reaplicação dos jogos junto às crianças, foi realizado em outro momento a reaplicação do ditado lacunado inicial, dessa vez com o intuito de averiguar o nível de explicitação alcançado pelas crianças com relação às regras trabalhadas. Os resultados obtidos no segundo ditado evidenciaram que a grande maioria dos sujeitos participantes avançaram na compreensão dessas regularidades da norma.

\section{RESULTADOS E DISCUSSÃO}

O início da pesquisa se deu na aplicação de um ditado com o intuito de diagnosticar as dificuldades ortográficas apresentadas pelas turmas de terceiro e quinto ano do Ensino Fundamental I pertencentes à rede municipal de ensino do Recife. Com os ditados em mãos, 
fizemos um levantamento dos erros ortográficos contextuais mais recorrentes em ambas às turmas, onde foi notado que a maior parte dos sujeitos apresentavam dúvidas quanto uso das regularidades do $\mathrm{M} / \mathrm{N}, \mathrm{C} / \mathrm{QU}$ e R/RR. A partir do levantamento inicial, foram selecionados, a princípio, 24 estudantes, sendo 12 crianças do terceiro ano e 12 crianças do quinto ano. No entanto, durante o desenvolvimento da pesquisa que demandou 09 encontros presenciais com os sujeitos participantes das duas turmas, tivemos uma baixa de 04 alunos, sendo 02 deles do terceiro ano e os outros 02 do quinto ano em decorrência de questões familiares e de saúde. Por esse motivo, o número de sujeitos participantes pensando inicialmente para a pesquisa foi reduzido para 20 estudantes.

O quadro 1 a seguir mostra os resultados obtidos durante o período de realização da pesquisa, suscitando que a maioria dos sujeitos participantes avançaram no tocante a compreensão das regras contempladas pelos jogos.

Quadro 1 - Levantamento dos resultados obtidos durante o período da pesquisa.

\begin{tabular}{|c|c|c|c|c|c|c|c|c|c|c|c|c|c|c|c|c|c|c|c|c|c|}
\hline \multirow{3}{*}{\multicolumn{2}{|c|}{$\begin{array}{c}\text { Regularidades } \\
\text { Contextuais }\end{array}$}} & \multicolumn{20}{|c|}{ Alunos } \\
\hline & & \multicolumn{10}{|c|}{$3^{\circ}$ ano } & \multicolumn{10}{|c|}{$5^{\circ}$ ano } \\
\hline & & 1 & 2 & 3 & 4 & 5 & 6 & 7 & 8 & 9 & 10 & 1 & 2 & 3 & 4 & 5 & 6 & 7 & 8 & 9 & 10 \\
\hline & & \multicolumn{20}{|c|}{ DP } \\
\hline \multirow{3}{*}{$\mathbf{R}$} & Brando & & & & & & & & & & & & & & & & & & & & \\
\hline & $\begin{array}{c}\text { Em início de } \\
\text { palavras }\end{array}$ & & & & & & & & & & & & & & & & & & & & \\
\hline & $\begin{array}{l}\text { Forte entre } \\
\text { vogais }\end{array}$ & & & & & & & & & & & & & & & & & & & & \\
\hline $\mathbf{M}$ & \multirow{2}{*}{$\begin{array}{l}\text { Em final de } \\
\text { sílabas }\end{array}$} & & & & & & & & & & & & & & & & & & & & \\
\hline $\mathbf{N}$ & & & & & & & & & & & & & & & & & & & & & \\
\hline $\mathrm{C}$ & \multirow{2}{*}{$\begin{array}{l}\text { Notando o } \\
\text { fonema } K\end{array}$} & & & & & & & & & & & & & & & & & & & & \\
\hline $\mathbf{Q U}$ & & & & & & & & & & & & & & & & & & & & & \\
\hline
\end{tabular}


Crianças que avançaram na compreensão das regras.

Crianças que permaneceram sem consolidar às regras.

Crianças que retrocederam na aplicação do ditado final.

Crianças que permaneceram acertando as palavras do ditado.

Ao olharmos para o quadro dos resultados obtidos durante o período da pesquisa, é notório que poucos alunos permaneceram sem consolidar às regras contempladas pelos jogos, sendo menor ainda o número de estudantes que retrocederam na aplicação do ditado final.

Esses dados nos mostram que a didática utilizada no processo de sistematização dessas regras de fato influenciou na aprendizagem dos sujeitos, ajudando-os a atingir o nível de explicitação quanto ao uso dessas regularidades da norma. Sendo assim, é certo afirmar que o uso de jogos foi uma estratégia didática fundamental para a assimilação das regras, elucidando que a aprendizagem mediada através desse recurso auxiliou o processo de ensinoaprendizagem de forma satisfatória - o que é evidente no quadro acima.

Como estratégia para ajudar os sujeitos participantes a atingirem os resultados pretendidos, a ludicidade trazida pelos jogos foi articulada com a ideia de dividir os estudantes em grupos, de modo que uma competição entre grupos fosse gerada para aquecer os processos de interação e participação entre os alunos para se chegar ao objetivo em comum. Os extratos a seguir mostram algumas situações ocorridas durante o processo de aplicação dos jogos.

Extrato 01 - Regularidade M/N - Jogo de classificação - $3^{\circ}$ ano

Pesquisadora: Grupo 2, qual foi a palavra que vocês completaram?

Alguns alunos do grupo 2: Pente!

Pesquisadora: A letra escolhida por vocês pra completar a palavra tá correta?

Alguns alunos do grupo 2: Sim!

Pesquisadora: Por quê?

Aluno 8: Porque não tem o $\mathrm{P}$ e nem o $\mathrm{B}$, então é com $\mathrm{N}$ !

Aluno 5: Tá certo, tia!

Pesquisadora: Vocês acertaram! É com N sim, já que não estamos diante de $\mathrm{P}$ e $\mathrm{B}$, usamos o N para as demais consoantes. Agora, qual é a próxima palavra da carta?

Alguns alunos do grupo 2: Sombra! 
Pesquisadora: Vocês usaram qual letra pra completar?

Alguns alunos do grupo 2: M!

Pesquisadora: Por quê?

Aluno 7: Porque o $\mathrm{M}$ vem antes de $\mathrm{P}$ e B!

Aluno 3: Ganhamos!

Pesquisadora: Muito bem! Vocês acertaram.

Nesse primeiro extrato, podemos destacar a verbalização da regra do $\mathrm{M} / \mathrm{N}$ como estratégia utilizada pelos alunos. Durante a aplicação desse jogo, foi nítido que os sujeitos participantes se atentavam a todo momento à consoante que sucedia a letra $\mathrm{M}$ ou $\mathrm{N}$ nas palavras presentes em suas cartas.

Extrato 02 - Regularidade M/N - Jogo de classificação - $5^{\circ}$ ano

Pesquisadora: Grupo 1, qual foi a palavra que vocês completaram?

Alguns alunos do grupo 1: Pombo!

Pesquisadora: A palavra tá correta? A letra escolhida por vocês pra completar a palavra tá correta?

Alguns alunos do grupo 1: Sim!

Pesquisadora: Por quê?

Aluno 7: Porque o M tem que ser antes de P e B!

Aluno 4: Todo mundo sabe que é o M!

Pesquisadora: Vocês acertaram! Realmente temos o M antes de P e B. Podem pegar a próxima palavra.

Alguns alunos do grupo 1: Em...empada!

Aluno 6: $\mathrm{N}$ !

Aluno 7: É com M... EM-PA-DA!

Aluno 6: Ah... aham...

Pesquisadora: Terminaram?

Aluno 6: Sim!

Pesquisadora: Qual foi a palavra?

Aluno 7: Empada! Com M!

Pesquisadora: Muito bem! Acertaram novamente. 
Nessa segunda situação com a mesma regularidade, podemos observar que além da verbalização da respectiva regra, os alunos corrigiram uns aos outros quanto a classificação do $\mathrm{M} / \mathrm{N}$ nas palavras de suas cartas. Observamos que no ato da correção, o aluno 7 fala a palavra separando por sílabas, apesar dessa forma não facilitar a escolha do M/N, o aluno 6 aceita de imediato a correção. Apesar dessa atitude do aluno 6 deixar dúvida se ele compreendeu o porquê do uso do $\mathrm{M}$ ou se apenas seguiu a orientação do colega, é possível verificar, de acordo com o quadro 2, que o aluno apresentou êxito na escrita dessa regra.

Extrato 03 - Regularidade M/N - Jogo de escrita $-5^{\circ}$ ano

Pesquisadora: Agora vocês vão montar as palavras correspondentes às figuras utilizando o alfabeto móvel... vamos lá?

Alguns alunos dos grupos 1 e 2: Sim, tia!

Pesquisadora: Ok. Grupo 2, qual foi a figura de vocês?

Aluno 6: É computador!

Pesquisadora: Vamos lá, montem a palavra.

Aluno 4: Cadê o A? Cadê o D-O?

Aluno 2: Vai precisar do R.

Aluno 4: Cadê o U aqui?

Aluno 2: R! R!

Pesquisadora: Os dois grupos terminaram?

Alguns alunos dos grupos 1 e 2: Sim!

Pesquisadora: Grupo 1, a palavra montada pelo grupo 2 tá correta?

Alguns alunos do grupo 1: Tá sim, tia!

Alguns alunos do grupo 2: Tá sim... É!

Pesquisadora: Por que vocês escolheram o M e não o N?

Aluno 2: Porque é com M!

Pesquisadora: Mas por quê?

Aluno 7: Porque tem o P... antes do P e do B é M!

Pesquisadora: Sim... muito bem! Agora é com o grupo 1, qual foi a palavra de vocês?

Alguns alunos do grupo 1: Anjo!

Pesquisadora: Grupo 2, tá tudo certo com a palavra? 
Alguns alunos do grupo 2: Tá... tá sim!

Pesquisadora: Grupo 2, por que vocês usaram o $\mathrm{N}$ aqui?

Aluno 8: Porque a gente não viu P e nem B... aí é com N!

Aluno 5: Se fosse $\mathrm{M}$ ia tá errado porque $\mathrm{M}$ é antes de $\mathrm{P}$ e $\mathrm{B}$ !

Pesquisadora: Muito bem! Os dois grupos acertaram.

Já no jogo de escrita da mesma regra os alunos iam falando o nome das letras para montar a palavra correspondente à figura da carta. Quando questionados o porquê do uso do $\mathrm{M}$ ou do $\mathrm{N}$ na palavra eles verbalizavam à regra.

Extrato 04 - Regularidade C/QU - Jogo de classificação - 5 ano

Pesquisadora: Grupos 1 e 2, esse é um jogo da memória, tá certo? Então vamos prestar atenção nas imagens, os pares devem ser iguais quanto a escrita das palavras, ou seja, tem que ter C ou QU em cada par. Vamos lá!

Aluno 6 (grupo 2): Coco e caju!

Aluno 7 (grupo 2): Os dois é com C!

Aluno 6 (grupo 2): Ponto de novo!

Pesquisadora: Grupo 1, quais figuras vocês pegaram agora?

Aluno 4 (grupo 1): Caderno e coração!

Pesquisadora: E aí? Formaram o par?

Aluno 8 (grupo 1): Tá certo, tia!

Alguns alunos do grupo 2: É, tá certo!

Pesquisadora: Grupo 2, sua vez!

Aluno 6 (grupo 2): Quiosque e quinze!

Aluno 7 (grupo 2): QU e QU!

Aluno 6 (grupo 2): Outro par!

Pesquisadora: Muito bem! Mais um par!

No jogo de classificação da regularidade C/QU os sujeitos participantes, em sua maioria, falavam o nome das letras iniciais das palavras correspondentes às figuras a medida que viravam as cartas do jogo, deixando claro que naquele momento, eles estavam acessando 
mentalmente seu repertório de palavras, buscando trazer à memória a regra em questão que os ajudariam a decidir à escrita da palavra para formarem os pares e pontuar na partida.

Extrato 05 - Regularidade C/QU - Jogo de escrita $-5^{\circ}$ ano

Pesquisadora: Grupos 1 e 2, agora temos um jogo de trilha! De acordo com o número da casa que o pino de vocês cair através do número sorteado no dado, eu pegarei a figura de mesmo número, ok? Par ou ímpar, vamos lá! (o grupo 1 começou a partida)

Aluno 9 (grupo 1): casinha 5!

Pesquisadora: Pronto, se montar a palavra corretamente vocês irão andar 5 casas, do contrário, permanecerão na marca de início do tabuleiro. A figura é... Colher!

Aluno 8 (grupo 1): É com U ou com O?

Alguns alunos do grupo 1: Cu...co...lherrr...

Aluno 8 (grupo 1): Cu... terminamos, tia!

Pesquisadora: Terminaram? Vamos ver! Grupo 2, vocês acham que eles montaram corretamente a palavra?

Aluno 7 (grupo 2): Tá errado, tia! É com O!

Aluno 6 (grupo 2): É cooolher!

Pesquisadora: Mas acertaram a regra do C ou QU na palavra?

Alguns alunos dos dois grupos: Sim! É com C mesmo!

Pesquisadora: Sim, é com C e escrevemos com O... CO-LHER, embora falamos "culher".

Grupo 2, agora é a vez de vocês! Joguem o dado pra ver o número de casas que vocês irão andar caso acertem a palavra.

Aluno 6 (grupo 2): Eeee... 6!

Pesquisadora: A figura é... brinquedos! Se formarem a palavra corretamente vocês irão permanecer na casa $6 \ldots$ vamos lá!

Aluno 6 (grupo 2): É com B, viu?

Aluno 7 (grupo 2): É com N aí...

Aluno 6 (grupo 2): Terminamos... tá certo, tia!

Pesquisadora: Eles acertaram grupo 1?

Aluno 8 (grupo 1): Tá... tá certo. 
Esse $5^{\circ}$ extrato nos mostra que a sistematização da regularidade C/QU através do jogo surtiu grande efeito à aprendizagem dos sujeitos no desafio da escrita das palavras, porém, outras dúvidas surgiram durante a aplicação do jogo, como exemplificado na pergunta do aluno 8: “É com U ou com O?”, referindo-se a sílaba inicial da palavra colher - tendo o grupo montado a palavra de acordo com o jeito que eles a pronunciam: "culher".

Extrato 06 - Regularidade R/RR - Jogo de classificação - $5^{\circ}$ ano

Pesquisadora: Agora vocês irão classificar nesse quadro os três tipos de R. Como já vimos, a letra $\mathrm{R}$ vem de diferentes maneiras nas palavras, tendo uma escrita e um som diferente. Por exemplo, temos o RR que fica no meio de palavras e que nunca vem no início ou no final... pra o R ter o som forte no meio das palavras temos que acrescentar outra letra R. Vamos lá, cada grupo ficará com um quadro.

(o aluno 2 verbalizou um pouco sobre o emprego do RR durante a fala da pesquisadora)

Aluno 4 (grupo 2): Barraca é com dois R! BAR-RA-CA... o mesmo de GAR-RA-FA!

Aluno 8 (grupo 1): Aqui... raquete fica com rede.

Pesquisadora: Terminaram de classificar?

Alguns alunos dos 3 grupos: Sim!

Pesquisadora: Então vamos lá! Veremos primeiro o quadro do grupo 1. Todas as palavras foram classificadas corretamente? Vamos ler as palavras que estão na coluna da figura urubu... VA-RA; ZE-RO; CA-RE-TA; CA-CHOR-RO.

Aluno 6 (grupo 2): Erraram!

Pesquisadora: O R de CA-CHOR-RO tremeu a língua?

Alguns alunos dos 3 grupos: Não!

Pesquisadora: Erraram apenas uma palavra dessa coluna. Vamos pra próxima! A figura é rede! Esse R tá aonde?

Alguns alunos dos 3 grupos: No começo!

Pesquisadora: Ok! Vamos ver uma por uma... RA-QUE-TE; RO-BÔ; MAR-RECO.

Aluno 6 (grupo 2): Errou! Marreco!

(a medida que a pesquisadora ia fazendo a leitura das palavras, os alunos iam dizendo se elas estavam ou não corretas de acordo com a figura da coluna correspondente ao R)

Pesquisadora: Pois é, essa foi a coluna do R inicial, a palavra MAR-RE-CO começa com a letra R? 
Alguns alunos do grupo 2: É a fila do RR.

Pesquisadora: Veremos a próxima coluna então... a figura é BOR-RA-CHA. Borracha tem quantos $\mathrm{R}$ ?

Alguns alunos dos 3 grupos: Tem dois!

Pesquisadora: Vamos ler... BUR-RO; ROU-PA...

Aluno 6 (grupo 2): Errou... errou!

Pesquisadora: Vamos continuar... TER-RA; XE-RI-FE.

Alguns alunos do grupo 2: Errou de novo!

Pesquisadora: o "RI" tremeu, né? Mas o grupo 1 errou apenas 4 palavras... foram muito bem! Agora é a vez do grupo 2! As figuras do quadro do grupo 2 foram: PI-RU-LI-TO; RO-DO; GAR-RA-FA. Vamos ler a coluna do pirulito primeiro! CA-RA-MU-JO; CA-RI-NHO; CARE-CA; CO-RO-A. Tá tudo certo?

Alguns alunos dos 3 grupos: Acertou!

Pesquisadora: Que tipo de R é esse?

Alguns alunos do grupo 2: É o fraco!

Pesquisadora: Muito bem! Agora vamos pra segunda coluna. Qual é o R aqui?

Aluno 2 (grupo 2): Rapadura!

(alguns alunos riram)

Aluno 6 (grupo 2): É o R do começo!

Pesquisadora: Vamos lá... RA-PA-DU-RA; RE-MÉ-DIO; RA-TOEI- RA; RA-IO. Todas têm o R inicial?

Alunos do grupo 2: Sim!

Pesquisadora: Muito bem! Acertaram todas as palavras. Agora vamos a última coluna.

Vem que tipo de $\mathrm{R}$ agora?

Aluno 6 (grupo 2): RR!

Pesquisadora: Vamos ver! BE-TER-RA-BA; TOR-RA-DA; BAR-RIO; CI-GAR-RA.

Alguns alunos do grupo 2: Acertamos tudo!

Pesquisadora: Agora é a vez do último grupo! Quadro do grupo 3 agora. As figuras foram: CO-RA-ÇÃO; RA-PO-SA; CAR-RO. Vamos ver se eles acertaram tudo na primeira coluna? CO-U-RO; CO-RO-NEL; JA-CA-RÉ; PI-RA-TA. Tudo certo?

Alguns alunos dos 3 grupos: Sim!

Pesquisadora: Agora vem o R de raposa, que é o R do... 
Aluno 2 (grupo 2): ... começo!

Pesquisadora: Muito bem! R inicial. E as palavras foram: RÁ-DI-O; RE-MO; RA-BO; RÉGUA.

Alguns alunos do grupo 2: Acertaram!

Pesquisadora: Agora vem a última coluna! Que R é esse aqui minha gente?

Alguns alunos dos grupos 1 e 2: Dois R!

Pesquisadora: E as palavras foram: JAR-RO; TOR-RE; FER-RO; BAR-RO. Acertaram tudo? Alguns alunos dos 3 grupos: Sim!

$O$ jogo de classificação da regularidade do $R / R R$ evidenciou que os alunos assimilaram bem o uso dos três tipos de $\mathrm{R}$ trazidos pelo jogo. Como estratégia utilizada podemos destacar a análise fonológica, onde os estudantes estabeleciam a relação letra-som para segmentação das sílabas das palavras, classificando assim os três tipos do R em sua respectiva coluna. Este foi o jogo que mais gerou expectativa nos estudantes. Diante do feedback positivo da pesquisadora, alguns membros dos grupos comemoravam e até se abraçavam, nos mostrando que eles realmente estavam gostando do momento de aprendizagem.

É possível observar, ainda, que o grupo 2 classifica a palavra MARRECO na coluna das palavras com R inicial. O erro pode ter sido provocado pela igualdade do som, ou seja, o som do R é o mesmo nas palavras, apesar da posição diferente.

\section{CONCLUSÕES}

A partir das informações levantadas neste trabalho, concluímos que o processo de ensino-aprendizagem das regularidades contextuais da norma através do uso de jogos trazem, de fato, resultados significativos, mostrando de forma imediata a qualidade da construção desse conhecimento nos estudantes, permitindo que o professor trabalhe de forma mais eficiente nas dificuldades reais apresentadas pelos sujeitos durante a realização dos jogos, permitindo-os alcançar o nível de explicitação almejado.

Sabendo que as regularidades da norma podem ser apresentadas aos estudantes de forma lúdica, é certo afirmar que o uso de jogos se faz necessário para que o processo de aprendizagem se afaste dos moldes de ensino da ortografia vistos no passado - práticas que já 
foram amplamente discutidas e eliminadas por vários estudiosos haja vista sua ineficiência quanto a aprendizagem da ortografia.

Conforme o exposto ao longo deste trabalho, a ortografia ainda é uma área de conhecimento com muitas lacunas a serem preenchidas no âmbito escolar, e, como consequência dessa "falta de atenção", muitos estudantes acabam se sentindo menos inteligentes por não dominar/entender a norma da própria língua, passando por situações de insegurança/constrangimento quando precisam escrever algo - o que é inevitável.

De acordo com o resultado que obtivemos, destacamos que as estratégias elaboradas pelas duas turmas de fato os ajudaram na compreensão das regularidades contextuais que foram sistematizadas pelos jogos. Os sujeitos participantes, em sua maioria, verbalizavam as regras a medida em que os jogos eram aplicados. A análise fonológica das palavras e a correção das palavras entre os participantes também foram estratégias bastante exploradas. Convém ressaltar, que a mediação docente durante os jogos também foi um fator decisivo na aprendizagem das regras.

Por este motivo, fomentamos que a aprendizagem mediada a partir do uso de jogos didáticos foram cruciais para assimilação das regras trabalhadas em nossos sujeitos participantes, deixando explícito que os conhecimentos normativos da língua podem ser assimilados de forma agradável, leve e em conjunto. Por via de regra, é válido deixar claro que a atitude docente também fez toda diferença durante esse processo, uma vez que o clima para a construção da aprendizagem é trazido e conduzido pelo professor.

Sendo assim, cabe aos professores e a escola um melhor tratamento à ortografia, não só por se tratar de um conhecimento imprescindível para a boa comunicação dos sujeitos, mas, também, por se tratar de um direito de compreender verdadeiramente como se dá a organização da língua materna, melhorando assim essa relação. 


\section{REFERÊNCIAS}

ALMEIDA, Tarciana Pereira da Silva. A relação entre a mediação docente e o desempenho ortográfico de alunos participantes de jogos de ortografia. $145 \mathrm{f}$. Dissertação (Mestrado) - Programa de Pós-Graduação em Educação. Universidade Federal de Pernambuco. 2013.2 Recife, Disponível em: http://repositorio.ufpe.br/handle/123456789/13330. Acesso em: 17/07/2018.

Bardin, L. Análise de Conteúdo. Lisboa: Edições 70, 1977.

MORAIS, Artur Gomes de. Representaciones Infantiles sobre la Ortografia Del Português. Tese de doutorado. Universitat de Barcelona. 1995.

. Ortografia: ensinar e aprender. 4. ed. São Paulo: Ática, 2003.

. A norma ortográfica do português: o que é? para que serve? como está organizada?. In: SILVA, Alexandre da.; MORAIS, Artur Gomes de.; MELO, Kátia Leal Reis de. (Org.). Ortografia na Sala de Aula. 1. ed., 1. reimp. Belo Horizonte: Autêntica, 2005.

MORAIS, Artur Gomes de.; SILVA, Alexandre da. A norma ortográfica é uma invenção necessária. In: SILVA, Alexandro da.; MORAIS, Artur Gomes de.; MELO, Kátia Leal Reis de. (Org.). Ortografia na Sala de Aula. 1. ed., 1. reimp. Belo Horizonte: Autêntica, 2005.

PIAGET. Jean. A psicologia da inteligência. Rio de Janeiro: Vozes, 2013.

TONELI, Neiva Costa. Convenções Ortográficas. In: FRADE, Isabel Cristina Alves da Silva; COSTA VAL, Maria da Graça; BREGUNCI, Maria das Graças de Castro (Orgs.). Glossário CEALE: termos de alfabetização, leitura e escrita para educadores. Belo Horizonte: UFMG/ Faculdade de Educação, 2014. P. 77-79.

VYGOTSKY, Lev Semenovich. A formação social da mente: o desenvolvimento dos processos psicológicos superiores. 5. ed. São Paulo: Martins Fontes, 1994. 